International Journal of Environmental Research and

Public Health

ISSN 1660-4601

www.mdpi.com/journal/ijerph

Review

\title{
Immigrant Mental Health, A Public Health Issue: Looking Back and Moving Forward
}

Usha George $^{1, *}$, Mary S. Thomson ${ }^{1, \dagger}$, Ferzana Chaze $^{2, \dagger}$ and Sepali Guruge ${ }^{3}$

1 Faculty of Community Services, Ryerson University, 99 Gerrard Street East, SHE-690; 350 Victoria Street, Toronto, ON M5B 2K3, Canada; E-Mail: marysusan.thomson@ryerson.ca

2 Community Studies, Sheridan College, 7899 McLaughlin Road, Brampton, ON L6Y 5H9, Canada; E-Mail: ferzana.chaze@sheridancollege.ca

3 School of Nursing; Ryerson University, Faculty of Community Services; 350 Victoria Street, Toronto, ON M5B 2K3, Canada; E-Mail: sguruge@ryerson.ca

$\dagger$ These authors contributed equally to this work.

* Author to whom correspondence should be addressed; E-Mail: ugeorge@ryerson.ca; Tel.: +1-416-979-5000 (ext. 6119); Fax: +1-416-979-5384.

Academic Editor: Sloane Burke Winkelman

Received: 22 July 2015 / Accepted: 20 October 2015 / Published: 27 October 2015

Abstract: The Mental Health Commission of Canada's (MHCC) strategy calls for promoting the health and wellbeing of all Canadians and to improve mental health outcomes. Each year, one in every five Canadians experiences one or more mental health problems, creating a significant cost to the health system. Mental health is pivotal to holistic health and wellbeing. This paper presents the key findings of a comprehensive literature review of Canadian research on the relationship between settlement experiences and the mental health and well-being of immigrants and refugees. A scoping review was conducted following a framework provided by Arskey and O'Malley (Int J Soc Res Methodol 8:19-32, 2005). Over two decades of relevant literature on immigrants' health in Canada was searched. These included English language peer-reviewed publications from relevant online databases Medline, Embase, PsycInfo, Healthstar, ERIC and CINAHL between 1990 and 2015. The findings revealed three important ways in which settlement affects the mental health of immigrants and refugees: through acculturation related 
stressors, economic uncertainty and ethnic discrimination. The recommendations for public health practice and policy are discussed.

Keywords: immigrants; settlement; mental health; public health; Canada

\section{Introduction}

Public health is concerned with the prevention of disease and with the promotion and protection of health in ways that promote social justice [1]. Mental health is central to health [2]. World Health Organization's (WHO) concept of mental health includes the promotion of mental well-being, the prevention and treatment of mental illness, as well as the rehabilitation of persons affected by mental illness ([2,3], p. 1). Research has recognized the vulnerability of immigrants and refugees in relation to mental health [4-12]. In 2011 over $20 \%$ of the total Canadian population was foreign-born. Over $17 \%$ of the foreign-born population were recent immigrants between 2006 and 2011 [13]. This paper presents the findings of a scoping review that focuses on the relationship between settlement experiences and mental health and wellbeing for immigrants and refugees in Canada. It builds on existing knowledge in capturing the mental health needs of diverse immigrant groups and makes a case for a holistic approach to public health intervention with immigrants and refugees. The mental health needs and importance of public health intervention for many small communities are not well captured in most studies using national samples.

In this review we are trying to narrow this gap in the literature. The paper is divided into four sections. Following this introduction we provide a brief background that helps us contextualise the impact of settlement experiences on immigrants' mental health. The second section details the methods used in the review. Section three discusses the findings of the review and section four discusses the recommendations for public health that emerge from the review.

\section{Background}

The process of adapting to the host country can be a stressful process, requiring psychological and socio-cultural adaptations [14]. Since the 1990s Canada has been accepting over 200,000 immigrants from around the world [15]. In the past few decades, these immigrants have typically migrated from countries in Asia and Africa. Coming from diverse cultures these racialized immigrants are likely to experience psychological stressors in the process of acculturation what Berry terms "acculturative stress" ([14], p. 9).

A majority of immigrants to Canada are "economic immigrants", accepted on the basis of their potential to contribute to the Canadian labor market through a points system based on language proficiency, professional qualifications and work experience. Research has demonstrated that though a majority of immigrants to Canada are carefully selected on basis of such a merit based point system, many are unable to find work commensurate with their education and training [16-18]. Despite having higher educational qualifications compared to native born persons, immigrants are more likely to be underemployed compared to native born Canadians [19,20]. 
Immigrants face many barriers in accessing employment in Canada such as the lack of acceptance of their foreign credentials by professional bodies and employers [21-23], language related barriers including discrimination on account of speaking English with a foreign accent [24-28], and lack of prior Canadian work experience [28-30]. The inability to secure suitable work forces many immigrants to take up low skilled, precarious work to survive [19,31]. Further, immigrants earn less on the job compared to native born persons doing similar work [32]. It is not surprising then, that immigrants are one of the five main poverty affected groups in Canada [33,34].

Though new immigrants to the country have better health than their native-born counterparts a phenomenon termed the "healthy immigrant effect" [35], their health advantage decreases over the years in the country $[35,36]$. The phenomenon is indicative of the negative impacts of migration on immigrant health [36].

That the health and mental health of an individual is influenced by many social factors is well established [3,37]. Migration has been acknowledged as one of the SDH [38] as migrants may face poverty, social isolation, and social inequities in their host countries. The Public Health Agency of Canada notes many factors as determinants of health including income, social networks, employment and having a minority culture and associated risk of marginalization [37]. As we have seen immigrants are vulnerable to many of these determinants.

\section{Experimental Section}

\section{Methodology}

This paper presents the findings of a scoping review that focuses on the relationship between settlement experiences and mental health for immigrants in Canada. Arskey and O'Malley [39] define scoping reviews as reviews that "aim to map rapidly the key concepts underpinning a research area and the main sources and types of evidence available" (p. 5). This methodology was deemed as most appropriate because of its systematic nature and its use in several other scoping reviews to map out a large area of research and explore issues in health among immigrants and refugees. Our objectives for conducting this review aligned with Arskey and O'Malley's objectives (i) to examine the extent, range and nature of research activity (ii) to summarize and disseminate research findings and (iii) to identify research gaps in literature. Our aim and broader research question was to map the key findings from published literature in our fields of interest i.e., immigrant and refugee health in Canada, health determinants including pre and post migration experiences and identify the gaps in this area of literature. We did not differentiate between immigrants and refugees for the purpose of this review. The stages involved in the review process, guided Arskey and O'Mallery's [39] framework included:

Stage 1: Identifying the broad research question: What is known from the existing literature about immigrant and refugee health in Canada over the last two decades?

Stage 2: Identifying the relevant studies: For locating and identifying the articles, we conducted an electronic literature search in consultation with an experienced librarian for peer reviewed English language articles from January 1990-August 2013 in Medline, Embase, PsycInfo, Healthstar, ERIC and CINAHL databases which contained desired terms in the title, abstract or keywords. Furthermore, we searched the literature online databases for any relevant recent articles from September 2013-May 
2015. The full set of search terms and inclusion and exclusion criteria for the selection of studies are given in Table 1. A flow chart for the search and selection and results are illustrated in Figure 1.

Table 1. Search Strategy \& Selection.

\begin{tabular}{|c|c|c|}
\hline \multicolumn{3}{|c|}{ Search Terms } \\
\hline \\
\hline \multicolumn{3}{|c|}{ race/racial/racism AND/OR } \\
\hline \multicolumn{3}{|c|}{ diversity/diverse AND/OR } \\
\hline \multicolumn{3}{|c|}{ religious/religion/spirituality AND/OR } \\
\hline \multirow{5}{*}{\multicolumn{3}{|c|}{$\begin{array}{c}\text { ethnic/ethno/minority/ethno cultural AND/OR } \\
\text { Health/Health beliefs/Mental health/Diseases/Chronic conditions AND } \\
\text { immigrant/emigrant/migrant/immigration/refugee/newcomer/non-status/precarious AND } \\
\text { Canada AND } \\
\text { English }\end{array}$}} \\
\hline & & \\
\hline & & \\
\hline & & \\
\hline & & \\
\hline \multirow{2}{*}{\multicolumn{3}{|c|}{$\begin{array}{l}\text { Exclusion Criteria } \\
\text { Literature Reviews }\end{array}$}} \\
\hline & & \\
\hline Focused on Canadian context & & Embase \\
\hline Peer reviewed research articles & Reports & PsycInfo \\
\hline Publication dates between 1990 and 2015 & $\begin{array}{l}\text { Ihesis } \\
\text { Diccertation }\end{array}$ & HealthStar \\
\hline Primary and secondary research articles & Book Chanters & ERIC \\
\hline Articles best fit" with the research question & $\begin{array}{l}\text { Book Cnapters } \\
\text { Case Studies }\end{array}$ & CINAHL \\
\hline
\end{tabular}

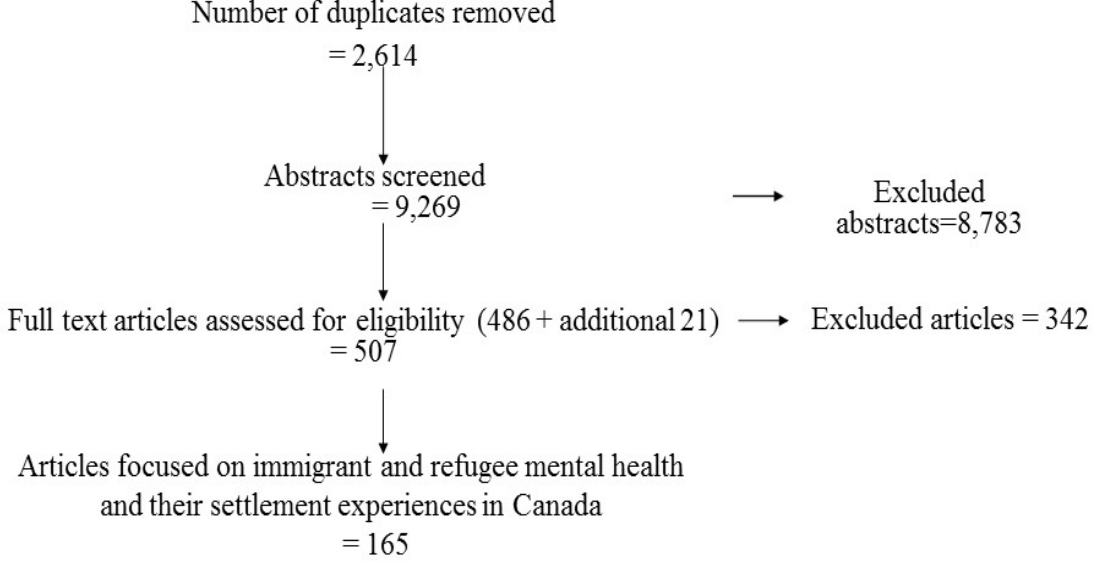

Figure 1. PRISMA flow diagram of review search screening process.

Stage 3: Selecting the studies: Due to the enormous number of studies on immigrant and refugee health we narrowed our focus to mental health of immigrants and refugees. Therefore, we modified our selection of studies to focus on immigrant and refugee mental health in Canada over the last two decades. We followed the WHO's $[3,40]$ conceptualization of mental health. After removing duplicates and irrelevant abstracts, 486 articles were chosen for full text review based on the above question and 
inclusion criteria. Full text of these 486 articles were exported electronically to Ref Works-COS, Pro Quest, LLC, a repository platform, to organize and store the references. A total of 165 articles [4-12,32,41-195] were selected for the final review.

Stage 4: Charting the data: These 165 articles were charted using Microsoft Excel to analyze in detail. Variables we charted include author/s, name of the journal, year of publication, title, aim of the study, focus area, study method and design, ethnicity, age, immigration status, gender, sample size, study setting, data collection, data analysis, major findings, limitations and implications for research, practice, and policy. Arksey and O'Malley's [38] framework was useful in relation to our broad research question, and remained flexible to clarify concepts and to revise the research question as we became familiar with literature.

Stage 5: Collating, summarizing, and reporting the data: The findings from the study were analysed and collated into three broad themes.

\section{Results and Discussion}

\subsection{Study Characteristics}

Study characteristics are outlined in Table 2 . All the studies were conducted in Canada, with almost half the articles reporting studies from province of Ontario $(n=72 ; 44 \%)$, followed by British Columbia $(n=28 ; 17 \%)$, Quebec $(n=24 ; 15 \%)$, Alberta $(n=20 ; 12 \%)$ and other provinces and multisite (more than one province) $(n=14: 8 \%)$. While a considerable number of the peer-reviewed published articles since 1990 focused on immigrants of all ethnicities, 34\%of the articles relate to the experiences of South Asian immigrants. This is not a surprise considering that South Asians accounted for $25 \%$ of the total visible minority population and $4.8 \%$ of Canada's total population [13]. Study participants included South Asians, Chinese, Koreans, Filipinos, Arabs, Haitian, Vietnamese, Afro Caribbean, Europeans, and Hispanics. Some studies (20\%) listed participants simply as "immigrants" and/or "refugees" without identifying the ethnic backgrounds of participants. Overall, $59 \%(n=97)$ more than half of the studies used quantitative methodology, $37 \%(n=61)$ used qualitative methodology, and remaining studies $4 \%(n=7)$ followed mixed methods combining qualitative and quantitative methods. Almost all the studies $93 \%(n=154)$ used cross sectional design and remaining $7 \%(n=11)$ used longitudinal design. Twelve percent $(n=21)$ of the studies used data from national surveys to conduct the study. One shortcoming of the review appears to be that most of the studies follow cross sectional design and therefore results could not confirm whether relationships between variables are casual in nature. Participants in the studies were heterogeneous in nature as they arrived in Canada from diverse cultural and ethnic backgrounds and their definitions of health in general, mental health and settlement experiences differed. Additional limitation of the reviewed studies is the culturally diverse interpretations of survey questions $[69,102]$. Inclusion of multiple survey questions might have reduced misinterpretations of survey questions. As pre migration mental health issues might also influence mental health and service utilization in the settlement period, there is a need for more longitudinal studies to verify the association between length of residence in the host country and the mental health and wellbeing of ethnic minorities $[4,42,196]$.

Table 2. Study characteristics. 


\begin{tabular}{ccc}
\hline Province Wide Distribution of Studies & N $(\boldsymbol{n}=\mathbf{1 6 5})$ & $\mathbf{\%}$ \\
\hline Ontario & 72 & 44 \\
British Columbia & 28 & 17 \\
Quebec & 24 & 15 \\
Alberta & 20 & 12 \\
Multisite (more than one province) & 14 & 8 \\
New Found Land & 3 & 2 \\
Nova Scotia & 1 & $<1$ \\
Manitoba & 1 & $<1$ \\
Moncton & 1 & $<1$ \\
Saskatoon & 1 & $<1$ \\
\hline Article type: & & \\
\hline Methods used: Qualitative & 61 & 37 \\
Methods used: Quantitative & 97 & 59 \\
Methods used: Mixed & 7 & 4 \\
\hline Design: & & \\
\hline Cross sectional & 154 & 93 \\
Longitudinal & 11 & 7 \\
\hline
\end{tabular}

The findings of the scoping review revealed three important ways in which settlement is related to the mental health of immigrants and refugees: acculturative stress, economic uncertainty and ethnic discrimination.

\subsection{Acculturative Stress}

Acculturative stress refers to the difficulties immigrants face in relation to the process of adapting to the host society. Acculturations to western lifestyles hold significant consequences for the mental health of many diverse immigrant groups $[175,197]$. For example, acculturation to western food habits has been shown to produce negative health consequences such as chronic illnesses in ethnic groups such as Italians, eventually leading to depressive symptomology [175]. Weaker cultural orientation towards the host culture is also linked to more depressive symptomology especially in immigrant older adults [5,197]. Acculturation of parents/parental perception and emotional behavior of Chinese children at school $(69,65)$ showed that acculturation pressures thrust immigrants into an arena of competing identities. Immigrant and Canadian-born Chinese children had different experiences of social and psychological adjustment in the school. Among aspects of acculturation, English proficiency and participation in Chinese cultural activities were positively associated with social competence and negatively associated with adjustment problems, particularly in immigrant Chinese children. These results indicate the involvement of contextual factors in children's social functioning and psychological well-being (73). The articles reviewed highlighted the impacts of post-migration acculturative-related stressors on the mental health of diverse immigrant groups [5,49,56,100,107,133,137,139,169,172,186,198] including Latin American men [140], immigrant mothers [111], and South Asian women [8,142].

Lack of social support and poverty that often accompany the migration and settlement process have been found to exacerbate mental ill health $[52,63,80,102]$. A part of the acculturation process is 
learning how to cope in Canada with limited social supports after immigration as migration disrupts many of the traditional supports that immigrants enjoyed in their home countries $[123,141,157,165]$.

Immigrants might have less access to social supports and underutilize mental health services in Canada due to language difficulties, transportation issues and linguistically and culturally inappropriate services $[32,48,57,60,69,75,78,83,86,96,98,132,134,138,176,199]$. The positive relationship between social supports and mental health has been well established [4,44,46,51-59,79,200-202]. A supportive, protective and hospitable environment is also necessary for maintaining good health and mental well-being [67]. Neighborhoods disadvantage and lack of community involvement has been found related to health problems and illness in immigrant adults, children and youth $[10,61,106]$. Acculturative stress has been known to differ among refugee groups based on ethnicity, immigration status, gender, and generational status [45,64]. Ataca and Berry [158] examined the acculturation and adaptation of married Turkish immigrants and found that there were differences in the acculturation experience and adaptation of working class and professional immigrants. Gender differences were most apparent in the low socioeconomic group; women in general were more psychologically vulnerable than men [83,131]. Results provided evidence for the role of acculturation-related hassles or stressors in the psychological distress for Vietnamese Canadian students [172] and Somali refugees [100], Youth felt overwhelmed when trying to fit in with the new culture while maintaining components of their own [97]. Abouguendia and Noels [164] examined general and acculturation related daily hassles in first and second generation South Asians in Canada and suggest that the two groups have different acculturation experiences. Study on the predictors of psychological well-being of Pakistani immigrants in Toronto, Canada suggested that increased availability of social supports can moderate acculturative stress among Pakistani immigrants and their families [11].

Refugees who have undergone traumatic encounters might have reduced ability to cope with acculturation changes [100]. This does not mean, however that economic immigrants are necessarily spared from such trauma. Post-arrival stresses has been known to increase mental health risk for refugees $[62,87]$. Chinese sojourners were found to have experienced poorer psychological health after arrival than pre-departure [203]. While newcomers are potentially underserved category, the needs of settled immigrants are no less [8,204]. Long after migrating, Somali refugees, Ethiopian immigrants, first and second generation immigrant women etc. were found to be at risk for stress-related dysfunction, because they suffered from a diminished capacity to cope with acculturation challenges and exhibited this as somatic symptoms [50,100,124,205,206]. Emotional problems and learning difficulties have been found in refugee children [174,182]. Not all groups of migrants are negatively affected during the acculturation stage. For example, post traumatic adaptation and psychological health has been known to improve with departure from the conflict among war zone immigrants residing in Toronto [101].

Children with parents who have adapted well to Canada as well as maintained their traditional beliefs and practices tend to do better after migration than children whose parents have completely assimilated [207]. Proficiency in English as well as participation in cultural activities have been found to be positively associated with social competence and negatively associated with adjustment problems among immigrant children $[73,178]$. The literature informs us that those who immigrate to Canada in childhood (and therefore have greater English language proficiency have a higher risk of mental health 
challenges [106]. In addition, Islam et al., [106] found that South Asian immigrants with better English/French proficiency had a higher risk of negative mental health outcomes.

\subsection{Economic Disadvantage}

The importance of financial resources for psychological and physical well-being of immigrant groups has been identified by a number of studies [6,32,33,74,171,184,208,209]. Many immigrants experience prolonged periods of low income and social exclusion in the post-migration context, which increase health disparities [34,210-212]. Research has pointed to the effects of poverty, un/under employment, financial insecurity and economic hardship on psychological health of immigrants at various stages of life [46,62,88,95,106,111,126,140,159,191,213,214], and of varied ethnicities [7-12,33, 89,104,151,163,180,184].

Compared to native born persons, immigrants are more likely to be represented among the unemployed populations [215]. Unemployment can pose a mental health threat in three different ways [178]: it leads to poverty giving less opportunity to acquire education and access to quality health care; it is a frustrating and stressful experience that has the potential to lead to more mental health problems and illness; and, it leads to unhealthy coping strategies namely drinking, gambling, smoking or drug abuse [89]. Effects of unemployment may also vary based on generational status. For example, Zunzunegui and colleagues [129] studied the relationship between community unemployment and the health of first and second generation immigrants and found that among first-generation immigrants, community unemployment was associated with psychological distress.

There are contradictions in the research in relation to the effect of underemployment on immigrant mental health. Tang and colleagues [12] found that underemployed migrants or those who suffered occupational stress do not fare much better in terms of mental health compared to unemployed migrants. On the contrary a study on the Southeast Asian refugees by Beiser and colleagues [193] revealed that underemployment, which is a threat to the mental health of the permanent resident Canadians, did not jeopardize the mental health of refugees.

Lack of recognition of their international qualifications and skills is a barrier to immigrant employment in Canada $[10,12]$. Immigrants can feel depressed that their past education is irrelevant to their current work [9,126]. Economically disadvantaged individuals report diminished levels of self-esteem [216] and strained family relationships [149] and lower life satisfaction [42]. The most frequently mentioned rehabilitation goals by both Canadian-born and immigrant consumers in the psychiatric rehabilitation program that included immigrants pertained to improving consumers' financial situation [136].

There are important intra-group differences in the relationship between economic disadvantage and migrant mental health. Beiser and colleagues [8] conducted a comparison of psychiatric illness in different cultures and demonstrated that though poverty created a risk of mental illness for both refugee and resident Canadians, the association between economic disadvantage and ill health proved stronger for refugees.

\subsection{Ethnic Discrimination}


Being a "visible minority" has been associated with high depressive symptoms as seen in the study of postnatal depression among immigrant women in Quebec [111]. Ethno-racial status and age emerged as key variables affecting the social exclusion of young immigrant mothers which in turn had deleterious effects on their health [105]. Research has found a relationship between perceived discrimination and psychological distress $[156,178,195]$. Depression symptoms, likely due to discrimination have also been found in samples of racialized immigrant university students and youths [76,193]. Whitley and Green [104] studied psychosocial experience of immigrant Black women in Montreal and reported three notable stressors emerged from their analyses: financial adversity, racism, and absent fathers. Furthermore, three notable buffers emerged from their analyses were families, the church, and cultural pride.

Discrimination has been identified as a social stressor [7,162,171,192,195]. Racial discrimination has been found to be an important risk factor for the mental health of diverse immigrant groups [66,84,104,115,121]. The results from a study by Noh and colleagues [121] emphasized the salience of subtle discrimination for the mental health of migrants. Beiser \& Hou [7] revealed that when the Southeast Asians encountered racial discrimination or unemployment, ethnic identity attachment amplified the risk of depressive affect. By contrast, a strongly held ethnic identity provided a psychological advantage for individuals experiencing difficulties with the dominant language. Discrimination also influences service utilization. In a study of immigrants and refugees living with HIV/AIDS in Toronto, Chen and colleagues [41] found that when participants encountered discrimination from medical practitioners it added to their stress and discouraged them from utilizing support in the future.

In summary, acculturation related stressors including the loss of social support in the migration process can impact mental health. Acculturative stress differs among immigrant groups based on ethnicity, immigration status, gender, and generational status. Immigrant mental health is impacted by their negative employment experiences in the settlement period and resultant economic hardships. Ethnic discrimination can also contribute to depression and psychological distress. It can also lead to barriers in the utilization of mental health services.

\subsection{Recommendations}

This scoping review provides insights into important areas for public health interventions. Public Health practitioners need to be cognizant of the impacts of settlement and its related featuresacculturative stress, economic difficulties and the experiences of discrimination while designing their interventions. There is a need to recognize the multiple and intersecting oppressions faced by immigrants and the community context in which they live [97]. Such an orientation recognizes the ways in which race, class, gender, age, sexual orientation and newcomer status work simultaneously to marginalize immigrant groups. The findings of the review call for health practitioners to recognize the vulnerability of immigrants in the settlement process and provide immigrants with resources to improve and expand their social networks. It reaffirms the importance of incorporating Social Determinants of Health into a holistic health promotion intervention and to advocate for more effective policies to facilitate newcomer settlement.

Increased availability of social supports can moderate acculturative stress [11,102,197,217]. Health practitioners need to help immigrants improve and access social and professional networks through 
programs such as mentorship or host programs. School-based interventions would be effective to reach out to immigrant parents [62,94,218]. A positive relationship between parents and schools offers opportunities to strengthen social supports that help parents adapt and in turn promote healthy emotional behavior in children [65,185].

A health promotion approach can be a useful one in approaching issues of immigrant mental health [97,219]. Such an approach can contribute toward addressing the social determinants of mental wellbeing and reduce health disparities for diverse immigrants [11,92,106]. Effective mental health promotion must consider the social determinants of health, and integrate the principles of social inclusion, access and equity into practice [79,90,220]. Ideally, mental health education would be integrated into the supports and services currently available to immigrants and their families [81]. Culturally appropriate public education and media campaigns should be developed and targeted to specific communities, using imagery and messages those are acceptable to community members. In order to improve mental health service, accessibility and delivery has to be re-examined considering community values, strengths, weaknesses and social inequities that help or hinder mental health promotion, and access to appropriate services for ethno linguistic communities enhanced through new models of collaborative care and services [122,137]. Early intervention services should monitor the pathways to care for young people of diverse ethnic backgrounds living within increasingly multiethnic and multilinguistic societies to address any disparities in accessing care [70].

The 2007 Mental Health Strategy for Canada ([221], p. 60) recognizes that immigrants and refugees face specific challenges that "puts their mental health at higher risk" including employment challenges and barriers to help seeking. The strategy recommends linguistically and culturally sensitive practice with immigrants groups. The strategy also recommends the development and implementation of mental health plans that meets the needs of immigrants and newcomers with their involvement ([221], p. 62). The authors of this paper suggest that such a plan should be broadened to also include strategies that promote immigrants' economic and social inclusion into society.

Health practitioners have an important role to play in advocating for better public policies impacting the settlement of newcomers and their mental health. Policy makers need to recognize the systemic barriers encountered by foreign-trained professional immigrants and ensure mechanisms for the fair evaluation of immigrant credentials [12]. Research has pointed out that limited policies exist to support the health of multicultural populations $[7,12,61,84,85,92,151]$. The Canadian health care system is one of the best in the world, yet one sees the contradictions that reveal the deeply structured hierarchies based on race, class and gender [122]. There is also a need for systemic change to formulate collaborative, community-based strategies for mental health promotion and interventions [84,90].

There is a need for more longitudinal research exploring the relationship between immigrant settlement and mental health. Ethnographies of single cultural groups, while often rich in depth and detail, do not examine shared adaptation experiences across diverse ethnic communities, nor can they readily inform policy and program in healthcare system that are required to serve multicultural client population [84].

Research has also identified the need to change social and professional attitude towards culturally and diverse individuals, and towards people who are economically disadvantaged [213,222-224], and who need culturally competent care [170,175]. There is also a clear need for mental health practitioners from diverse ethnic and linguistic backgrounds [149, 223,224]. 


\section{Conclusions}

The findings from the scoping review identified that settlement related experiences are important to consider in relation to immigrant mental health. The findings call for public health practitioners to be cognizant of these relationships in their interventions. There is a need for practitioners to intervene at the preventive level to address settlement related stressors and to advocate for policies that will effectively address labour market inequalities and discrimination in society.

The results of this scoping review are compatible for what has been described for other countries like USA, Australia, France and Germany. Immigration to Canada, USA, Australia, France and Germany accounts for about $93 \%$ of total migratory flows globally. Among the four countries, Canada and Australia receive the highest number of immigrants in the world [225,226]. Although immigration policies in Canada, Australia are similar, it is slightly different for USA and UK. All these countries have English as an official language. Canada and UK provide free healthcare. The experiences/difficulties faced by immigrants during the settlement phase in their host countries and their impact on mental health and well being are compatible. For e.g., Changes that occur in immigrants' employment structure are common in Canada, USA, UK and Australia and these changes can have a significant effect on psychological well being and adaptation [180,226].

\section{Limitations}

A limitation of the study is that we did not conduct bibliographic and/or grey literature searches. Furthermore, we did not assess the quality of the studies nor the methods used by each researcher. We reviewed articles written and published in English only. This might have led to omission of interesting research published in other languages especially French given the focus on Canada. Another short coming of this review is that we did not differentiate between immigrants and refugees. Although we knew that the pre-and post -migration experiences and mental health well-being/issues can be different for immigrants and refugees, there was no possibility for us to undertake two different scoping reviews for the two groups with the available time and resources. Another limitation to note is that since most of the studies followed cross sectional design, relationships between variables may be casual in nature and this may affect the results.

\section{Acknowledgments}

We acknowledge the funding received from Ministry of Health and Long Term Care, Ontario, Canada (MOHLTC Grant \# 06662). 


\section{Author Contributions}

Usha George conceived the study, acquired funding, designed and participated in preparation of manuscript, Mary S. Thomson designed the study, collected literature, acquired data, conducted analysis and interpretation of data and participated in the preparation of manuscript, Ferzana Chaze interpreted the data and participated in preparation of the manuscript, Sepali Guruge contributed to the study concept, design and preparation of the manuscript.

\section{Conflicts of Interest}

The authors declare no conflict of interest.

\section{References}

1. Silva, D.S.; Smith, M.; Upshur, R. Disadvantaging the disadvantaged: when public health policies and practices negatively affect marginalized populations. Can. J. Public Health 2013, 104, 410-412.

2. Herman, H.; Jane-Llopis, E. Mental health promotion in public health. Promot. Educ. 2005, 12, 42-47.

3. WHO. Mental Health. 2014. Available online: http://www.who.int/topics/mental_health/en/ (accessed on 7 November 2014).

4. Chadwick, K.A.; Collins, P.A. Examining the relationship between social support availability, urban center size, and self-perceived mental health of recent immigrants to Canada: A mixedmethods analysis. Soc. Sci. Med. 2015, 128, 220-230.

5. Srirangson, A.; Thavorn, K.; Moon, M.; Noh, S. Mental health problems in Thai immigrants in Toronto, Canada. Int. J. Cult. Ment. Health 2013, 6, 156-169.

6. Beiser, M.; Hou, F. Language acquisition, unemployment and depressive disorder among Southeast Asian refugees: A 10-year study. Soc. Sci. Med. 2001, 53, 1321-1334.

7. Beiser, M.N.; Hou, F. Ethnic identity, resettlement stress and depressive affect among Southeast Asian refugees in Canada. Soc. Sci. Med. 2006, 63, 137-150.

8. Beiser, M.; Cargo, M.; Woodbury, M.A. A comparison of psychiatric disorder in different cultures: Depressive typologies in Southeast Asian refugees and resident Canadians. Int. J. Methods Psychiatr. Res. 1994, 4, 157-172.

9. Dean, J.A.; Wilson, K. "Education? It is irrelevant to my job now. It makes me very depressed..." exploring the health impacts of under/unemployment among highly skilled recent immigrants in Canada. Ethn. Health 2009, 14, 185-204.

10. Jafari, S.; Baharlou, S.; Mathias, R. Knowledge of determinants of mental health among Iranian immigrants of BC, Canada: “A qualitative study”. J. Immigr. Minor. Health 2010, 12, 100-106.

11. Jibeen, T.; Khalid, R. Predictors of Psychological well-being of Pakistani Immigrants in Toronto, Canada. Int. J. Intercult. Relat. 2010, 34, 452-464.

12. Tang, T.N.; Oatley, K.; Toner, B.B. Impact of life events and difficulties on the mental health of Chinese immigrant women. J. Immigr. Minor. Health/Center Minor Public Health 2007, 9, 281-290. 
13. Statistics Canada. Immigration and Ethnocultural Diversity in Canada. National Household Survey 2011. Available online: http://www12.statcan.gc.ca/nhs-enm/2011/as-sa/99-010-x/99010-x2011001-eng.cfm (accessed on 21 October 2013).

14. Berry, J.W. Immigration, acculturation, and adaptation. Appl. Psychol. 1997, 46, 5-34.

15. Citizenship and Immigration Canada. Retrieved from Background paper developed within the framework of the IOM project "Assisting Migrants and Communities (AMAC): Analysis of social determinants of health and health inequalities" 2013. Available online: http://www.rcn.org.uk/_data/assets/pdf_file/0007/438838/01.12_Health_inequalities_and_the_s ocial_determinants_of_health.pdf(accessed on 21 October 2014)

16. George, U.; Chaze, F.; Fuller-Thomson, E.; Brennenstuhl, S. Underemployment and life satisfaction: A Study of internationally trained engineers in Canada. J. Immigr. Refug. Stud. 2012, 10, 407-425.

17. Reitz, J.G. Tapping immigrants' skills. IRPP Choices 2005, 11, 1-15.

18. Sparks, R.J.; Wolfson, W.G. Settlement in the Workplace. The Settlement Needs of Employed Newcomers. An Exploratory Study. 2001. Available online: http:/atwork.settlement.org/ downloads/Settlement_in_the_Workplace.pdf (accessed on 13 August 2014).

19. Galarneau, D.; Morissette, R. Immigrants' Education and Required Job Skills. Perspectives, Statistics Canada, 2008. Available online: http://www.statcan.gc.ca/pub/75-001-x/2008112/ pdf/10766-eng.pdf (accessed on 13 August 2014).

20. HRDC-Human Resources and Skills Development, Annual report, Canada, 2013. Available online: http://www12.hrsdc.gc.ca (accessed on 22 October 2015).

21. Esses, V.M.; Dietz, J.; Bennett-AbuAyyash, C.; Joshi, C. Prejudice in the Workplace: The Role of Bias against Visible Minorities in the Devaluation of Immigrants' Foreign-Acquired Qualifications and Credentials. Canadian Issues 2007. Available online: http://canada.metropolis.net/pdfs/ cdn_issues_CITC_spring07.pdf (accessed on 29 September 2014).

22. George, U.; Chaze, F. Credential assessment of internationally trained professionals: How effective is the process for the purpose of securing employment? J. Immigr. Refug. Stud. 2012, 10, 124-130.

23. Shan, H. Shaping the re-training and re-education experiences of immigrant women: The credential and certificate regime in Canada. Int. J. Lifelong Educ. 2009, 28, 353-369.

24. Banerjee, R. Income growth of new immigrants in Canada: Evidence from the survey of labour and income dynamics. Relat. Ind. 2009, 64, 486-508.

25. Boyd, M.; Cao, X. Immigrant language proficiency, earnings, and language policies. Can. Stud. Popul. 2009, 36, 63-86.

26. Munro, M.J. A primer on accent discrimination in the Canadian context. TESL Can. J. 2003, 20, 38-51.

27. Schellenberg, G.; Maheux, H. Immigrants' perspectives on their first four years in Canada: Highlights from three waves of the Longitudinal Survey of Immigrants to Canada. Available online: http://www.statcan.gc.ca/pub/11-008-x/2007000/9627-eng.htm (accessed on 22 October 2015).

28. Xue, L. Portrait of an Integration Process. Available online: http:/www.cic.gc.ca/english/pdf/ research-stats/portrait-integr-process-e.pdf (accessed on 8 June 2014). 
29. Liu, E. A Descriptive Study of Employers' Attitudes and Practices in Hiring Newcomer Job Seekers. CERIS-The Ontario Metropolis Centre. 2007. Available online: $\mathrm{http}: / /$ www.ceris.metropolis.net/?p=1416 (accessed on 6 June 2014).

30. Slade, B.L. From High Skill to High School: The Social Organization of "Canadian Work Experience” for Immigrant Professionals 2008. Available online: http://books.google.ca/books/ about/From_High_Skill_to_High_School_The_Socia.html?id=ZD-Ywu-HkoEC\&redir_esc=y (accessed on 13 September 2014).

31. George, U. Immigration and Settlement in Canada. Available online: http://www.amazon.ca/gp/product/1419674528/ref=olp_product_details?ie=UTF8\&me= (accessed on 30 April 2014 ).

32. Li, H.Z.; Browne, A.J. Defining mental illness and accessing mental health services: Perspectives of Asian Canadians. Can. J. Commun. Ment. Health 2000, 19, 143-159.

33. Fleury, D. A Study of Poverty and Working Poverty among Recent Immigrants to Canada. 2007. Available online: http://publications.gc.ca/collections/collection_2008/hrsdc-rhdsc/HS28-1212007E.pdf (accessed on 8 June 2014).

34. Hatfield, M. Vulnerability to Persistent Low Income. Available online: http://www.horizons.gc.ca/eng/book/export/html/1778 (accessed on 6 June 2014).

35. Kennedy, S.; McDonald, J.T.; Biddle, N. The Healthy Immigrant Effect and Immigrant Selection: Evidence from Four Countries. Available online: http://socserv2.socsci.mcmaster.ca/ $\sim$ sedap/p/sedap164.pdf (accessed on 3 September 2015 ).

36. Fuller-Thomson, E.; Noack, A.M.; George, U. Health decline among recent immigrants to Canada: Findings from a nationally-representative longitudinal survey. Can. J. Public Health 2011, 102, 237-280.

37. PHAC. Public Health Agency of Canada. What Determines Health? Available online: What Determines Health? Available online: http://www.phac-aspc.gc.ca/ph-sp/determinants/indexeng.php (accessed on 9 January 2013).

38. Davies, A.A.; Basten, A.; Frattini, C. Migration: A Social Determinant of the Health of Migrants. 2009. Available online: http://ec.europa.eu/ewsi/UDRW/images/items/docl_9914_392596 992.pdf (accessed on 8 June 2014).

39. Arksey, H.; O’Malley, L. Scoping Studies: Towards a methodological Framework. Int. J. Soc. Res. Methodol. 2005, 8, 1-28.

40. Thomson, M.S.; Chaze, F.; George, U.; Guruge, S. Improving immigrant populations' access to mental health services in Canada: A review of barriers and recommendations. J. Immigr. Minor. Health 2015, doi:10.1007/s 10903-015-0175-3.

41. Chen, B.Y.Y.; Li, A.T.; Fung, K.P.; Wong, J.P. Improving access to mental health services for racialized immigrants, refugees, and non-status people living with HIV/AIDS. J. Health Care Poor Underserved 2015, 26, 505-518.

42. Kim, I.H.; Noh, S. Changes in life satisfaction among Korean immigrants in Canada. Int. J. Cult. Ment. Health 2015, 8, 60-71.

43. Puyat, J.H. Is the influence of social support on mental health the same for immigrants and non-immigrants? J. Immigr. Minor. Health 2013, 15, 598-605. 
44. O’Mahony, J.M.; Donnelly, T.T.; Bouchal, S.R.; Este, D. Cultural background and socioeconomic influence of immigrant and refugee women coping with postpartum depression. $J$. Immigr. Minor. Health 2013, 15, 300-314.

45. Gagnon, A.J.; Carnevale, F.; Mehta, P.; Stewart, D.E. Developing population interventions with migrant women for maternal-child health: A focused ethnography. BMC Public Health 2013, doi:10.1186/1471-2458-13-471.

46. O'Mahony, J.M.; Donnelly, T.T. How does gender influence immigrant and refugee women's postpartum depression help-seeking experiences. J Psychiatry Ment. Health Nurs. 2013, 20, 714-725.

47. Sethi, B. Newcomers health in Brantford and the counties of brant, Haldimand and Norfolk: Perspectives of newcomers and service providers. J. Immigr. Minor. Health 2013, 15, 925-931.

48. Lai, D.W.L.; Surood, S. Effect of service barriers on health status of aging South Asian immigrants in Calgary, Canada. Health Soc. Work 2013, doi:10.1093/hsw/hls065.

49. Gagnon, A.J.; Dougherty, G.; Wahoush, O. International immigration to Canada: The post birth health of mothers and infants by immigration class. Soc. Sci. Med. 2013, 76, 197-207.

50. Mamisachvili, L.; Ardiles, P.; Mancewicz, G. Culture and Postpartum mood problems: Similarities and differences in the experiences of first and second generation Canadian women. J. Transcult. Nurs. 2013, 24, 164-170.

51. MacDonnell, J.A.; Dastjerdi, M.; Bokore, N.; Khanlou, N. Becoming resilient: Promoting the mental health and wellbeing of immigrant women in a Canadian context. Nurs. Res. Pract. 2012, 4, 1-10.

52. Alvi, S.; Zaidi, A.; Ammar, N.; Culbert, L. A comparative and exploratory analysis of sociocultural factors and immigrant women's mental health in a Canadian context. J. Immigr. Minor. Health 2012, 14, 420-432.

53. O’Mahony, J.M.; Donnelly, T.T.; Bouchal, S.R.; Este, D. Barriers and facilitators of social supports for immigrant and refugee women coping with postpartum depression. Adv. Nurs. Sci. 2012, 35, 42-56

54. Stewart, D.E.; Gagnon, A.J.; Merry, L.A.; Dennis, C.-L. Risk factors and health profiles of recent migrant women who experienced violence associated with pregnancy. J. Women's Health 2012, $21,1100-1106$.

55. Ganann, R.; Sword, W.; Black, M.; Carpio, B. Influence of maternal birthplace on postpartum health and health service use. J. Immigr. Minor. Health 2012, 14, 223-229.

56. Miszkurka, M.; Goulet, L.; Zunzunegui, M.V. Immigrant status, antenatal depressive symptoms, and frequency and source of violence: What's the relationship? Arch. Women's Ment. Health 2012, 15, 387-396.

57. O’Mahony, J.M.; Este, D.; Bouchal, R.S. Using critical ethnography to explore issues among immigrant and refugee women seeking help for postpartum depression. Issues Ment. Health Nurs. 2012, 33, 735-742.

58. Dastjerdi, M. The case of Iranian immigrants in the greater Toronto area: A qualitative study. Int. J. Equity Health 2012, 11, 1-8.

59. Hynie, M.; Crooks, V.A.; Barragan, J. Immigrant and refugee social networks: determinants and consequences of social support among women newcomers to Canada. Can. J. Nurs. Res. 2011, 43, 26-46. 
60. Ganesan, S.; Mok, H.; McKenna, M. Perception of mental illness: Preliminary exploratory research at a cross-cultural outpatient psychiatric clinic. Int. J. Soc. Psychiatry 2011, 7, 81-89.

61. Beiser, M.; Zilber, N.; Simich, L.; Youngmann, R.; Zohar, A.H.; Taa, B.; Hou, F. Regional effects on the mental health of immigrant children: Results from the New Canadian Children and Youth Study. Health Place 2011, 17, 822-829.

62. Beiser, M.; Simich, L.; Pandalgat, N. Stresses of passage, balms of resettlement and posttraumatic stress disorder among Sri Lankan Tamils in Canada. Can. J. Psychiatry 2011, 56, 333-340.

63. Donnelly, T.T.; Hwang, J.J.; Este, D.; Ewashen, C.; Adair, C.; Clinton, M. If I was going to kill myself, I wouldn't be calling you. I am asking for help: Challenges influencing immigrant and refugee women's mental health. Issues Ment. Health Nurs. 2011, 32, 279-290.

64. Durbin, A.; Lin, E.; Taylor, L.; Callaghan, R.C. First-generation immigrants and hospital admission rates for psychosis and affective disorders: An ecological study in Ontario. Can. J. Psychiat. 2011, 56, 418-426.

65. Hamilton, H.; Marshall, L.; Rummens, J.A.; Fenta, H.; Simich, L. Immigrant parents' perceptions of school environment and children's mental health and behavior. J. Sch. Health 2011, 81, 313-319.

66. Rousseau, C.; Hassan, G.; Moeau, N.; Thomba, B.D. Perceived discrimination and its association with psychological distress among newly arrived immigrants before and after 11 September 2001. Am. J. Public Health 2011, 101, 909-915.

67. Stafford, M.; Newbold, B.K.; Ross, N. Psychological distress among immigrants and visible minorities in Canada: A contextual analysis. Int. J. Soc. Psychiatry 2011, 57, 428-441.

68. Haque, A. Mental health concepts in Southeast Asia: Diagnostic considerations and treatment implications. Psychol. Health Med. 2010, 15, 127-134.

69. Chen, C.; Smith, P.; Mustard, C. The prevalence of over-qualification and its association with health status among occupationally active new immigrants in Canada. Ethn. Health 2010, 15, 601-619.

70. Archie, S.; Akhtar-Danesh, N.; Norman, R.; Malla, A.; Roy, P.; Zipursky, R.B. Ethnic diversity and pathways to care for a first episode of psychosis in Ontario. Schizophr. Bull. 2010, 36, 688-701.

71. Asbridge, M.; Payne, E.; Cartwright, J.; Mann, R. Driving under the influence of alcohol: Examining ethno-specific rates and the mediating effects of psychological distress and harmful and problematic drinking. Accid. Anal. Prev. 2010, 42, 1408-15.

72. Chen, A.W.; Kazanjian, A.; Wong, H.; Goldner, E.M. Mental health service use by Chinese immigrants with severe and persistent mental illness. Can. J. Psychiatry 2010, 55, 35-42.

73. Chen, X.; Tse, H.C.-H. Social and psychological adjustment of Chinese Canadian children. Int. J. Behav. Dev. 2010, 34, 330-338.

74. Chow, H.P. Growing old in Canada: Physical and psychological well-being among elderly Chinese immigrants. Ethn. Health 2010, 15, 61-72.

75. Chow, W.; Law, S.; Andermann, L.; Yang, J.; Leszcz, M.; Wong, J.; Sadavoy, J. Multi-family psycho-education group for assertive community treatment clients and families of culturally diverse background: A pilot study. Community Ment. Health J 2010, 46, 364-371.

76. Costigan, C.L.; Koryzma, C.M.; Hua, J.M.; Chance, L.J. Ethnic identity, achievement, and psychological adjustment: Examining risk and resilience among youth from immigrant Chinese families in Canada. Cult. Divers. Ethn. Minor. Psychol. 2010, 2, 264-273. 
77. Hickling,F.W.; Guzder, J.; Robertson-Hickling, H.; Snow, S.; Kirmayer, L. Psychic centrality: Reflections on two psychohistoriographic cultural therapy workshops in Montreal. Transcult. Psychiat. 2010, 47, 136-158.

78. Lai, D.W.L.; Surood, S. Types and Factor Structure of Barriers to Utilization of Health Services among Aging South Asians in Calgary, Canada. Can. J. Aging 2010, 29, 249-258.

79. O’Mahony, M.J.; Donnelly, T.T. A postcolonial feminist perspective inquiry into immigrant women's mental health care experiences. Issues Ment. Health Nurs. 2010, 31, 440-449.

80. Miszkurka, M.; Goulet, L.; Zunzunegui, M.V. Contributions of immigration to depressive symptoms among pregnant women in Canada. Can. J. Public Health 2010, 101, 358-364.

81. Tieu, Y.; Konnert, C.; Wang, J. Depression literacy among older Chinese immigrants in Canada: A comparison with a population-based survey. Int. Psychogeriatr. 2010, 22, 1318-1326.

82. White, J.; Morris, J. Precarious spaces: Risk, responsibility and uncertainty in school-based suicide prevention programs. Soc. Sci. Med. 2010, 71, 2187-2194.

83. Guruge, S.; Khanlou, N.; Gastaldo, D. Intimate male partner violence in the migration process. Intersection of gender, race and class. J. Adv. Nurs. 2009, 66, 103-113.

84. Gadalla,T.M. Ethnicity and seeking treatment for depression: A Canadian national study. Can Ethnic Studies 2010. 41, 233-245.

85. Beiser, M. Resettling refugees and safeguarding their mental health: Lessons learned from the Canadian Refugee Resettlement Project. Transcult. Psychiatry 2009, 46, 539-583.

86. Chen, A.W.; Kazanjian, A.; Wong, H. Why do Chinese Canadians not consult mental health services: Health status, language or culture? Transcult. Psychiatry 2009, 46, 623-641.

87. Jorden, S. Supportive and unsupportive social adaptation and psychological distress among somali refugees exposed to collective or personal traumas. J. Cross Cult. Psychol. 2009, doi:10.1177/0022022109339182.

88. Landy, C.K.; Sword, W.; Valaitis, R. The experiences of socioeconomically disadvantaged postpartum women in the first 4 weeks at home. Qual. Health Res. 2009, 19, 194-206.

89. Reitmanova, S.; Gustafson, D.L. Primary mental health care information and services for St. John's visible minority immigrants: Gaps and opportunities. Issues Ment. Health Nurs. 2009, 30, 615-623.

90. Reitmanova, S.; Gustafson, D.L. Mental health needs of visible minority immigrants in a small urban center: Recommendations for policy makers and service providers. J. Immigr. Minor. Health 2009, 11, 46-56.

91. Schaffer, A.; Cairney, J.; Cheung, A.; Veldhuizen, S; Kurdyak, P.; Levitt, A. Differences in prevalence and treatment of bipolar disorder among immigrants: Results from an epidemiologic survey. Can. J. Psychiatry 2009, 54, 734-742.

92. Simich, L.; Maiter, S.; Ochocka, J. From social liminality to cultural negotiation: Transformative processes in immigrant mental wellbeing. Anthropol. Med. 2009, 16, 253-266.

93. Gadalla, T.M. Determinants, correlates and mediators of psychological distress: A longitudinal study. Soc. Sci. Med. 2009, 68, 2199-2205.

94. Fung, K.; Wong, Y-L.R. Factors influencing attitudes towards seeking professional help among East and Southeast Asian Immigrant and Refugee women. Int. J. Soc. Psychiatry 2007, 53, 216-231. 
95. Ahmed, A.; Stewart, D.E.; Teng, L.; Wahoush, O.; Gagnon, A.J. Experiences of immigrant new mothers with symptoms of depression. Arch. Womens Ment. Health 2008, 11, 295-303.

96. Chen, A.W.; Kazanjian, A.; Wong, H. Determinants of mental health consultations among recent Chinese immigrants in British Columbia, Canada: Implications for mental health risk and access to services. J. Immigr. Minor. Health 2008, 10, 529-540.

97. Khanlou, N. Young and new to Canada: Promoting the mental wellbeing of immigrant and refugee female youth. Int. J. Ment. Health Addict. 2008, 6, 514-516.

98. Lai, D.W.L.; Surood, S. Predictors of depression in aging South Asian Canadians. J. Cross Cult. Gerontol. 2008, 23, 57-75.

99. Mason, R.; Hyman, I.; Berman, H.; Guruge, S.; Kanagaratnam, P.; Manuel, L. Violence is an international language: Tamil women's perceptions of intimate partner violence. Violence Women 2008, 14, 1397-1412.

100. Matheson, K.; Jorden, S.; Anisman, H. Relations between trauma experiences and psychological, physical and neuroendocrine functioning among Somali refugees: Mediating role of coping with acculturation stressors. J. Immigr. Minor. Health 2008, 10, 291-304.

101. Stermac, L.; Brazeau, P.; Kelly, T.C. Traumatic stress and mental health among war-zone immigrants in Toronto. Int. J. Health Promot. Educ. 2008, 46, 57-64.

102. Stewart, D.E.; Gagnon, A.; Saucier, J.-F.; Wahoush, O.; Dougherty, G. Postpartum depression symptoms in newcomers. Can. J. Psychiatry 2008, 53, 121-124.

103. Tiwari, S.K.; Wang, J. Ethnic differences in mental health service use among White, Chinese, South Asian and South East Asian populations living in Canada. Soc. Psychiat. 2008, 43, 866-871.

104. Whitley, R.; Green, S. Psychological stressors and buffers affecting black women in Montreal. Can. J. Community Ment. Health 2008, 27, 37-48.

105. Whitley, R.; Kirmayer, L.J. Perceived stigmatisation of young mothers: An exploratory study of psychological and social experience. Soc. Sci. Med. 2008, 66, 339-348.

106. Islam, F.; Khanlou, N.; Tamim, H. South Asian populations in Canada: Migration and mental health. BMC Psychiatry 2014, 14, 1-13

107. Hsu, L.; Alden, L.E. Cultural influences on willingness to seek treatment for social anxiety in Chinese- and European-heritage students. Cult. Divers. Ethn. Minor. Psychol. 2008, 14, 215-223.

108. Morrow, M.; Smith, J.E.; Lai, Y. Shifting landscapes: Immigrant women and postpartum depression. Health Care Women Int. 2008, 29,593-617.

109. Reitmanova, S.; Gustafson, D.L. "They can't understand it": Maternity healthcare needs of immigrant Muslim women in St. John's, Newfoundland. Matern. Child Health J. 2008, 12, 101-111.

110. Zelkowitz, P.; Saucier, J.F.; Wong, T. Stability and change in depressive symptoms from pregnancy to two months postpartum in child bearing immigrant women. Arch. Women's Ment. Health. 2008, 11, 1-11.

111. Mechakra-tahiri, S.; Zunzunegui, M.V. Self-Rated Health and Postnatal Depressive Symptoms among Immigrant Mothers in Québec. Women Health 2007, 45, 1-17.

112. Piat, M.; Ricard, N.; Sabetti, J.; Beauvais, L. The values and qualities of being a good helper: A qualitative study of adult foster home caregivers for persons with serious mental illness. Int. J. Nurs. Stud. 2007, 44, 1418-1429. 
113. O’Mahony, J.M.; Donnelly, T.T. Health care providers' perspective of the gender influences on immigrant women's mental health care experiences. Issues Ment. Health Nurs. 2007, 28, 1171-1188.

114. O’Mahony, M.J.; Donnelly, T.T. The influence of culture on immigrant women's mental health care experiences from the perspectives of health care providers. Issues Ment. Health Nurs. 2007, 28, 453-471.

115. Acharya, M.P.; Northcott, H.C. Mental distress and the coping strategies of elderly Indian immigrant women. Transcult. Psychiatry 2007, 44, 614-636.

116. Etowa, J.; Keddy, B.; Egbeyemi, J.; Eghan, F. Depression: The "invisible grey fog" influencing the midlife health of African Canadian women. Int. J. Ment. Health Nurs. 2007, 16, 203-213.

117. Lai, D.W.L.; Chou, S.B.Y. Predictors of health service barriers for older Chinese immigrants in Canada. Health Soc. Work 2007, 32, 57-65.

118. Lai, D.W.L.; Tsang, K.T. Relationships between Culture and Health Status: A multisite study of the older Chinese in Canada. Can. J. Aging 2007, 26, 171-183.

119. Georgiades, K.; Boyle, M.H.; Duku, E. Contextual influences on children's mental health and school performance: The moderating effects of family immigrant status. Child Dev. 2007, 78, $1572-1591$.

120. Hong, J.J.; Woody, S.R. Cultural mediators of self-reported social anxiety. Behav. Res. Ther. 2007, 45, 1779-1789.

121. Kirmayer, L.J.; Weinfeld, M.; Burgos, G.; du Fort, G.G.; Lasry, J.C.; Young, A. Use of health care services for psychological distress by immigrants in an urban multicultural milieu. Can. J. Psychiatry 2007, 52, 295-304.

122. Noh, S.; Kaspar, V.; Wickrama, K.S. Overt and subtle racial discrimination and mental health: Preliminary findings for Korean immigrants. Am. J. Public Health 2007, 97, 1269-1274.

123. Teng, L.; Robertson, B.E.; Stewart, D. Healthcare worker's perceptions of barriers to care by immigrant women with postpartum depression: An exploratory qualitative study. Arch. Women's Ment. Health 2007, 10, 93-101.

124. Fenta, H.; Hyman, I.; Noh, S. Mental health service utilization by Ethiopian immigrants and refugees in Toronto. J. Nerv. Ment. Dis. 2006, 194, 925-934.

125. Schmidt, F.; McKinnon, L.; Chattha, H.K.; Brownlee, K. Concurrent and predictive validity of the psychopathy checklist: Youth version across gender and ethnicity. Psychol. Assess 2006, 18, 393-401.

126. Simich, L.; Hamilton, H.; Baya, B.K. Mental distress, economic hardship and expectations of life in Canada among Sudanese newcomers. Transcult. Psychiat. 2006, 43, 418-444.

127. Wester, S.R.; Kuo, B.C.H.; Vogel, D.L. Multicultural coping: Chinese Canadian adolescents, male gender role conflict, and psychological distress. Psychol. Men Masc. 2006, 7, 83-100.

128. Whitley, R.; Kirmayer, L.J.; Groleau, D. Understanding immigrants' reluctance to use mental health services: A qualitative study from Montreal. Can. J. Psychiat. 2006, 51, 205-209.

129. Zunzunegui, M.-V.; Forster, M.; Gauvin, L.; Raynault, M.-F.; Williams, J.D. Community unemployment and immigrants' health in Montreal. Soc. Sci. Med. 2006, 63, 485-500.

130. Jarvis, G.E.; Kirmayer, L.J.; Weinfeld, M.; Lasry, J. Religious practice and psychological distress: The importance of gender, ethnicity and immigrant status. Transcult. Psychiat.2005, 42, 657-675.

131. Chiu, L.; Ganesan, S.; Clark, N.; Morrow, M. Spirituality and treatment choices by South and East Asian women with serious mental illness. Transcult. Psychiat. 2005, 42, 630-656. 
132. Chen, A.W.; Kazanjian, A. Rate of mental health service utilization by Chinese immigrants inBritish Columbia. Can. J. Public Health 2005, 96, 50-51.

133. Jarvis, G.E.; Kirmayer, L.J.; Jarvis, G.K.; Whitley, R. The role of Afro-Canadian status in police or ambulance referral to emergency psychiatric services. Psychiat. Serv. 2005, 56, 705-710.

134. Ganesan, S.; Janze, T. Overview of culturally based mental health care in Vancouver. Transcult. Psychiatry 2005, 42, 478-490.

135. Lai, D.W.L. Prevalence and correlates of depressive symptoms in older Taiwanese immigrants in Canada. J. Chin. Med. Assoc. 2005, 68, 118-125.

136. Lecomte, T.; Wallace, C.J.; Perreault, M.; Caron, J. Consumers' goals in psychiatric rehabilitation and their concordance with existing services. Psychiatr. Serv. 2005, 56, 209-211.

137. Nadeau, L.; Measham, T. Immigrants and mental health services: increasing collaboration with other service providers. Child Adolesc. Psychiat. Rev. 2005, 14, 73-76.

138. Taylor, L.E.; Taylor-Henley, S.; Doan, L. Older immigrants: Language competencies and mental health. Can. J. Commun. Ment. Health 2005, 24, 23-33.

139. Uskul, A.K.; Greenglass, E. Psychological wellbeing in a Turkish-Canadian sample. Anxiety Stress Coping 2005, 18, 269-278.

140. Pottie, K.; Brown, J.B.; Dunn, S. The resettlement of Central American men in Canada: From emotional distress to successful integration. Refugee 2005, 22, 101-111.

141. Ahmad, F.; Shik, A.; Vanza, R.; Stewart, D.E. Voices of South Asian women: Immigration and mental health. Women Health 2004, 40, 113-130.

142. Wong, R.Y-L.; Tsang, A.K.T. When Asian immigrant women speak: From mental health to strategies of being. Am. J. Orthopsychat. 2004, 74, 456-466.

143. Beiser, M.; Wickrama, K.A.S. Trauma, time and mental health: A study of temporal reintegration and Depressive Disorder among Southeast Asian refugees. Psychol. Med. 2004, 34, 899-910.

144. Khanlou, N. Influences on adolescent self-esteem in multicultural Canadian secondary schools. Public Health Nurs. 2004, 21, 404-411.

145. Lai, D.W.L. Impact of culture on depressive symptoms of elderly Chinese immigrants. Can. J. Psychiat. 2004, 49, 820-827.

146. Lai, D.W.L. Depression among elderly Chinese-Canadian immigrants from Mainland China. Chin. Med. J. 2004, 117, 677-683.

147. Zelkowitz, P.; Schinazi, J.; Katofsky, I. Factors associated with depression in pregnant immigrant women. Transcult. Psychiat. 2004, 41, 445-464.

148. Rousseau, C.; Drapeau, A. Premigration exposure to political violence among independent immigrants and its association with emotional distress. J. Nerv. Ment. Dis. 2004, 192, 852-856.

149. Sadavoy, J.; Meier, R.; Yuk Mui Ong, A.; Yuk, M. Barriers to Access to Mental Health Services for Ethnic Seniors: The Toronto Study. Can. J. Psychiat. 2004, 49, 192-199.

150. Tweed, R.G. Culture, Stress, and Coping: Internally- and externally-targeted control strategies of European Canadians, East Asian Canadians, and Japanese. J. Cross Cult. Psychol. 2004, 35, 652-668.

151. Beiser, M.; Simich, L.; Pandalangat, N. Community in Distress: Mental health needs and help-seeking in the Tamil Community in Toronto. Int. Migr. 2003, 41, 233-245.

152. Lai, D.W.L. Health and predictors of health among older Chinese-Canadians in British Columbia. BC Med. J. 2003, 45, 382-390. 
153. Lai, D.W.L.; Yuen, C.T.Y. Gender, physical limitation, and depression among elderly Chinese. Int. J. Ment. Health Addict. 2003, 1, 1557-1584.

154. Safdar, S.F.; Lay, C.H. The relations of immigrant-specific and immigrant-nonspecific daily hassles to distress controlling for psychological adjustment and cultural competence. J. Appl. Soc. Psychol. 2003, 33, 299-320.

155. Smith, A.; Lalonde, R.N. Racelessness in a Canadian context? Exploring the link between Black students' identity, achievement, and mental health. J. Black Psychol. 2003, 29, 142-164.

156. Wu, Z.; Noh, S.; Kaspar, V.; Schimmele, C.M. Race, ethnicity, and depression in Canadian society. J. Health Soc. Behav. 2003, 44, 426-441.

157. Donnelly, T.T. Contextual analysis of coping: Implications for immigrants' mental health care. Issues Ment. Health Nurs. 2002, 23, 715-732.

158. Ataca, B.; Berry, J.W. Psychological, sociocultural, and marital adaptation of Turkish immigrant couples in Canada. Int. J. Psychol. 2002, 37, 13-26.

159. Beiser, M.; Hou, F.; Hyman, I.; Tousignant, M. Poverty, family process, and the mental health of immigrant children in Canada. Am. J. Public Health 2002, 92, 220-227.

160. Dossa, P. Narrative mediation of conventional and new "mental health" paradigms: Reading the stories of immigrant Iranian women. Med. Anthropol. Q. 2002, 16, 341-359.

161. Edlund, M.J.; Wang, P.S.; Berguland, P.A. Dropping out of mental health treatment: Patterns and predictors among epidemiological survey respondents in the United States and Ontario. Am. J. Psychiat. 2002, 159, 845-851.

162. Moghaddam, F.M.; Taylor, D.M.; Ditto, B.; Jacobs, K.; Bianchi, E. Psychological distress and perceived discrimination: A study of women from India. Int. J. Intercult. Relat. 2002, 26, 381-390.

163. Wickrama, K.S.; Beiser, M.; Kaspar, V. Assessing the longitudinal course of depression and economic integration of south-east Asian refugees: An application of latent growth curve analysis. Int. J. Methods Psychiatr. Res. 2002, 11, 154-168.

164. Abouguendia, M.; Noels, K.A. General and acculturation-related daily hassles and psychological adjustment in first and second-generation South Asian immigrants to Canada. Int. J. Psychol. 2001, 36, 163-173.

165. Ali, A.; Toner, B.B. Symptoms of depression among Caribbean women and Caribbean-Canadian women: An investigation of self-silencing and domains of meaning. Psychol. Women Q. 2001, 36, 163-173.

166. Bottorff, J.L.; Johnson, J.L.; Venables, L.J.; Grewal, S.; Popatia, N.; Hilton, B.A.; Clarke, H.; Sumel, P.; Bilkhu, S.; Sandhu, G. Voices of immigrant South Asian women: Expressions of health concerns. J. Health Care Poor Underserved 2001, 12, 392-403.

167. Lai, D.W.L. Depression among the elderly Chinese in Canada. Can. J. Aging 2000, 19, 409-429.

168. Lai, D.W.L. Prevalence of depression among the elderly Chinese in Canada. Can. J. Public Health 2000, 91, 64-66.

169. Ryder, A.G.; Alden, L.E.; Paulhus, D.L. Is acculturation unidimensional or bidimensional? A head-to-head comparison in the prediction of personality, self-identity, and adjustment. J. Pers. Soc. Psychol. 2000, 79, 49-65.

170. Schreiber, R.; Stern, P.N.; Wilson, C. The contexts for managing depression and its stigma among black West Indian Canadian women. J. Adv. Nurs. 1998, 27, 510-517. 
171. Noh, S.; Beiser, M.; Kaspar, V.; Hou, F.; Rummens, J.; Beiser, M. Perceived racial discrimination, and coping: Depression, A Study of Southeast Asian Refugees in Canada. J. Health Soc. Behav. 1999, 40, 193-207.

172. Lay, C.; Nguyen, T. The Role of acculturation-related and acculturation non-specific daily hassles: Vietnamese-Canadian students and psychological distress. Can. J. Behav. Sci. 1998, 30, 172-181.

173. Majumdar, B.; Ladak, S. Management of family and workplace stress experienced by women of colour from various cultural backgrounds. Can. J. Public Health 1998, 89, 48-52.

174. Rousseau, C.; Drapeau, A. Parent-child agreement on refugee children's psychiatric symptoms: A transcultural perspective. J. Am. Acad. Child Adolesc. Psychiatry 1998, 37, 629-636.

175. Ponzo, G.M.; Gucciardi, E; Weiland, M. Gender, ethnocultural and psychosocial barriers to diabetes self -management in Italian men and women with Type 2 Diabetes. Behav. Med. 2006, 31, 153-160.

176. Chappell, N.L.; Lai, D.W.L. Healthcare service use by Chinese seniors in British Columbia. J. Cross Cult. Gerontol. 1998, 13, 21-37.

177. Beiser, M.; Hyman, I. Refugees' time perspective and mental health. Am. J. Psychiatry 1997, 154, 996-1002.

178. Short, K.H.; Johnston, C. Stress, maternal distress, and children's adjustment following immigration: The buffering role of social support. J. Consult. Clin. Psychol. 1997, 65, 494-503.

179. Noh, S.; Avison, W.R. Asian immigrants and the stress process: A study of Koreans in Canada. J. Health Soc. Behav. 1996, 37, 192-206.

180. Aycan, Z.; Berry, J.W. Impact of employment-related experiences on immigrants' psychological weil-being and adaptation to Canada. Can. J. Behav. Sci. 1996, 28, 240-251.

181. Pawliuk, N.; Grizenko, N.; Chan-Yip, A.; Gantous, P.; Mathew, J.; Nguyen, D. Acculturation style and psychological functioning in children of immigrants. Am. J. Orthopsychiatry 1996, 66, 111-121.

182. Rousseau, C.; Drapeau, A.; Corin, E. School performance and emotional problems in refugee children. Am. J. Orthopsychiatry 1996, 66, 239-251.

183. Baker, C.; Arseneault, A.M.; Gallant, G. Resettlement without the support of an ethnocultural community. J. Adv. Nurs. 1994, 26, 1064-1072.

184. Beiser, M.; Johnson, P.J.; Turner, R.J. Unemployment, underemployment and depressive affect among Southeast Asian refugees. Psychol. Med. 1993, 23, 731-743.

185. Pepler, D.J.; Lessa, I. the mental health of Portuguese children. Can. J. Psychiatry 1993, 38, 46-50.

186. Sands, E.T.; Berry, J.W. Acculturation and mental health among Greek Canadians in Toronto. Can. J. Commun. Ment. Health 1993, 12, 117-124.

187. Guzder, J; Yohannes, S; Zelkowitz, P. Helpseeking of immigrant and native born parents: A qualitative study from a montreal child day hospital. J. Can. Acad. Child Adolesc. Psychiatry 2013, 22, 275-281.

188. Noh, S.; Speechley, M.; Kaspar, V.; Wu, Z. Depression in Korean immigrants in Canada (I): Method of the study and prevalence of depression. J. Nerv. Ment. Dis. 1992, 180, 543-607.

189. Noh, S.; Wu, Z.; Speechley, M.; Kaspar, V. Depression in Korean immigrants in Canada (II): Correlates of gender, work, and marriage. J. Nerv. Ment. Dis. 1992, 180, 543-607. 
190. Noh, S.; Avison, R.; Kasper, V. Depressive symptoms among Korean immigrants: Assessment of a translation of the centre for epidemiologic studies- depression scale. Psychol. Assess. 1992, 4, 84-91.

191. Chandrasena, R.; Beddag, V.; Fernado, M.L. Suicide among immigrant psychiatric patients in Canada. B. J. Psych. 1991, 159, 707-709.

192. Pak, A.W.; Dion, K.L.; Dion, K.K. Social-psychological correlates of experienced discrimination: Test of double jeopardy hypothesis. Int. J. Intercult. Relat. 1991, 15, 243-254.

193. Dion, K.L.; Giordano, C. Ethnicity and sex as correlates of depression symptoms in a Canadian university sample. Int. J. Soc. Psychiat. 1990, 36, 30-41.

194. Dion, K.K.; Dion, K.L.; Pak, A.W. The role of self-reported language proficiencies in the cultural and psychosocial adaptation among members of Toronto, Canada's Chinese community. J. Asian Pac. Commun. 1990, 1, 173-189.

195. Moghaddam, F.M.; Ditto, B.; Taylor, D.M. Attitudes and attributions related to psychological symptomatology in Indian Immigrant women. J. Cross Cult. Psychol. 1990, 21, 335-350.

196. Lou, Y.; Beaujot, R. What Happens to the Healthy Immigrant Effect: The Mental Health of Immigrants to Canada; Discussion paper No. 05-15; Population Studies Centre, University of Western Ontario: London, ON, Canada, 2005; Volume 7.

197. Kuo, B.C.H.; Chong, V.; Joseph, J. Depression and its psychosocial correlates among older Asian Immigrants in North America: A critical review of two decades' research. J. Aging Health 2008, 20, 615-652.

198. Stewart, M.; Anderson, J.; Beiser, M.; Makarimba, E.; Neufeld, A.; Simich, and L. Multicultural meanings of social support among immigrants and refugees. Int. Migr. 2008, 46, 123-159.

199. Guruge, S.; Matsuoka, A.; Agrawal, S.; Beaulieu, M. Development of a Program of Research on prevention of Abuse among Older Immigrant Women; Department of Justice of Canada: London, ON, Canada 2011; p. 111. Available online: http://www.maltraitancedesaines.com/en/writtenproductions/contenu/117-research-reports-or-reports-produced-for-the-government (Accessed on 22 October 2015).

200. Dennis, C.L.; Hodnett, E. Psychosocial and psychological interventions for treating postpartum depression. Cochrane Database Syst. Rev. 2007, doi: 10.1002/14651858.

201. Jhangiani, S.J.; Vadeboncoeur, J.A. Health care "as usual": the insertion of positive psychology in Canadian mental health discourse. Mind Cult. Act. 2010, 17, 169-184.

202. Stewart, M.; Shizha, E.; Makwarimba, E. Challenges and barriers to services for immigrant seniors in Canada: "You are among others but you feel alone". Int. J. Migr. Health Soc. Care 2011, 7, 16-32.

203. Stewart, M.; Makwarimba, E.; Barnfather, A.; Letourneau, N.; Neufeld, A. Researching reducing health disparities: Mixed methods approaches. Soc. Sci. Med. 2008, 66, 1406-1417.

204. Kirmayer, L.J.; Narasiah, L.; Munoz, M.; Rashid, M.; Ryder, A.G.; Guzder, J.; Hassan, G.; Rousseau, C.; Pottie, K. Common mental health problems in immigrants and refugees: General approach in primary care. CMAJ 2011, 183, 959-967.

205. Fenta, H.; Hyman, I.; Noh, S.; Rourke, S. Somatic symptoms in a community sample of Ethiopian immigrants in Toronto, Canada. Int. J. Cult. Ment. Health 2009, 3, 1-15. 
206. Fenta, H.; Hyman, I.; Noh, S. Health service utilization by ethiopian immigrants and refugees in Toronto. J. Immigr. Minor. Health. 2007, 9, 349-357.

207. Hyman, I.; Beiser, M.; Vu, N. The Mental health of refugee children in Canada. Refuge 1996, 15, 4-8.

208. Islam, F. Examining the "Healthy Immigrant Effect" for mental health in Canada (Review). UTMJ. 2013, 90, 169-175.

209. Balgopal, P.R. Social Work Practice with Immigrants and Refugees; Columbia University: New York, NY, USA, 2000.

210. Asanin, J.; Wilson, K. "I spent nine years looking for a doctor": Exploring access to healthcare among immigrants in Mississauga, Ontario, Canada. Soc. Sci. Med. 2008, 66, 1271-1128.

211. Simich, L.; Beiser, M.; Stewart, M.; Makarimba, E. Providing social support for immigrants and refugees in Canada: Challenges and directions. J. Immigr. Health 2005, 7, 259-268.

212. Li, P.S. Earning Disparities between Immigrants and Native-born Canadians. Can. Rev. Sociol. 2000, 73, 289-311.

213. Shakya, Y.B. Access Alliance, Toronto, Onatrio, Canada. Summary Where are the Good Jobs? Available online: http://accessalliance.ca/wp-content/uploads/2015/03/Summary_Where-are-theGood-Jobs-Report-2013.pdf. (accessed on 15 September 2015).

214. Bagley, C.R. Mental health and social adjustment of elderly Chinese immigrants in Canada. Canada's Ment. Health 1993, 41, 6-10.

215. Galarneau, D.; Morissette, R. Immigrants: Settling for Less? Statistics Canada, Perspectives on Labour and Income. 2004. Available online: http://www.statcan.gc.ca/pub/75-001-x/10604/6921eng.htm (accessed on 21 October 2013).

216. Taylor, D.M.; Usborne, E. When I know who "we" are, I can be "me": The primary role of cultural identity clarity for psychological well-being. Transcult. Psychiatry 2010, 47, 93-111.

217. Guruge, S.; Thomson, M.S.; George, U.; Chaze, F. Social support, social conflict, and immigrant women's mental health in a Canadian context: A scoping review. J. Psych. Ment. Health Nurs. 2015, 22, 655-667.

218. Huang, K.Y.; Calzada, E.; Kamboukos, D. applying public health frameworks to advance the promotion of mental health among Asian American Children. Asian Am. J. Psychol. 2014, 5, $145-152$.

219. Khanlou, N.; Beiser, M.; Cole, E.; Freire, M.; Hyman, I.; Kilbride, K.M. Mental Health Promotion among Newcomer Female Youth: Post-Migration Experiences and Self-Esteem. 2002. Available online: http://citeseerx.ist.psu.edu/viewdoc/download? (accessed on 21 October 2013).

220. Healthy People 2020. Social Determinants of Health. 2014. Available online: http://www.healthypeople.gov/2020/topicsobjectives2020/overview.aspx?topicid=39 (accessed on 8 June 2015).

221. Mental Health Commission of Canada. The Mental Health Strategy for Canada. Available online: www. Mentalhealthcommission.ca.2012 (accessed on 19 November 2013).

222. Pope, J.F.; Arthur, N. Socioeconomic status and class: A challenge for the practice of psychology in Canada. Can. Psychol. 2009, 50, 55-65. 
223. Hansson, E.; Tuck, A.; Lurie, S.; McKenzie, K. For the Task Group of the Services Systems Advisory Committee, Mental Health Commission of Canada. Available online: http://www.mentalhealthcommission.ca/English/system/files/private/Diversity_Issues_Options_ Report_ENG_0.pdf (accessed on 15 September 2015).

224. Mental Health Well Being of Immigrants. Mental Health Well Being of Immigrants in Toronto: A report to the Ministry of Health and Long Term care. Available online: www.stmichaels hospital.com/knowledgeinstitute/.../download.php?id (accessed on 15 September 2015).

225. Islam, F.; Oremus, M. Mixed methods immigrant mental health in Canada: A Systematic Review. J. Immigr. Minor. Health 2014, 16, 1284-1289.

226. Cando, M.B.; Brown, J. Experiences of Newcomer Youth in the Home Environment. M.A. School of graduate and post doctoral studies, Western University, London, ON, Canada. April 2015.

(C) 2015 by the authors; licensee MDPI, Basel, Switzerland. This article is an open access article distributed under the terms and conditions of the Creative Commons Attribution license (http://creativecommons.org/licenses/by/4.0/). 